\title{
Erratum to: Enhanced Tolerance to Cold in Common Bean Treated with Biostimulant
}

\author{
Vanessa do Rosário Rosa ${ }^{1}$ Anna Luiza Farias dos Santos ${ }^{1}$. Adinan Alves da Silva ${ }^{2}$. \\ Mariana Peduti Vicentini Sab ${ }^{1}$. Flávio Barcellos Cardoso ${ }^{3}$. Mario Antonio Marin ${ }^{3} \cdot$ Marcelo de Almeida Silva $^{1}$
}

Published online: 7 January 2021

๑) Springer-Verlag GmbH Deutschland, ein Teil von Springer Nature 2021

\section{Erratum to:}

\section{Gesunde Pflanzen 2020}

https://doi.org/10.1007/s10343-020-00526-2

Unfortunately, there was an error in the author order. The correct order is:

Vanessa do Rosário Rosa ${ }^{1}$, Anna Luiza Farias dos Santos ${ }^{1}$, Adinan Alves da Silva ${ }^{2}$, Mariana Peduti Vicentini $\mathrm{Sab}^{1}$, Flávio Barcellos Cardoso ${ }^{3}$, Mario Antonio Marin ${ }^{3}$, Marcelo de Almeida Silva ${ }^{1 *}$.

The original article has been corrected.

The online version of the original article can be found under https://doi.org/10.1007/s10343-020-00526-2.

$\square$ Marcelo de Almeida Silva marcelo.a.silva@unesp.br

1 School of Agricultural Sciences, Laboratory of Ecophysiology Applied to Agriculture (LECA), Department of Crop Production, São Paulo State University (UNESP), Botucatu, SP, Brazil

2 Laboratory of Ecophysiology and Crop Production, Federal Goianian Institute (IF Goiano), Rio Verde, GO, Brazil

3 Heringer Fertilizers Inc., Paulínia, SP, Brazil 